\title{
Knuth's Art of Recovering from Errors
}

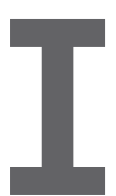

ReAlly EnJOYed Donald E. Knuth reminiscing in Edward Feigenbaum's interview with him ("The 'Art' of Being Donald Knuth," July 2008). Who else would have moved to Stanford University to slow down?

Knuth's self-effacing modesty notwithstanding, I would like to challenge anyone to examine the literature preceding Knuth's contribution to algorithms and compiler theory. There was good work, but it was Knuth who set the field on its feet. I'm now looking forward to learning how he "solves the problem of typesetting" (see Aug. 2008). I personally made the mistake of using Microsoft Word for my Ph.D. thesis (completed 1996). More recently, I decided that the topic-efficient object-oriented programming for shared-memory multiprocessors-was of interest again due to the rise of multicore computers and reformatted it as a book. What a nightmare. I promised myself I'd use LaTeX for every Ph.D. I ever write again.

Philip Machanick, Taringa, Australia

\section{Dependable Design and the Consequences of Failure}

Leah Hoffman's news article "In Search of Dependable Design" (July 2008) was a good overview of some of the issues affecting software and system reliability, explaining how system dependability might be improved through good engineering practice. This is similar to a subject I covered in Technology Review (Apr. 1987) on software reliability.

However, Hoffman did not adequately discuss the theoretical limits that add to the risk of real-time, interactive applications. Peter Wegner's Communications article "Why Interaction Is More Powerful Than Algorithms" (May 1997) pointed out that interaction systems are not only difficult to verify but also formally incomplete, impossible to verify. Where the risk of system failure cannot be further reduced due to such limits, effort must be directed in- stead at reducing the consequences of failure.

Ron Enfield, Cherry Hill, NJ

\section{Technology Supports, Doesn't Supplant the Social Compact}

In "Information Accountability" (June 2008), Daniel J. Weitzner et al. so exaggerated the good points they made that they created a false dichotomy between computing technologies (such as encryption) and societal conventions and laws, summing up in the article's final sentence: "Technology will better support freedom by relying on these social compacts than by seeking to supplant them." They were wrong. Technology does not seek to supplant social compacts but indeed seeks to add to them, legitimately.

Alex Simonelis, Montreal

\section{Proud to Be a Member}

My usual routine on finding Communications in my mailbox is to spend a few minutes flipping through the pages, then throw it on top of a pile of other unread magazines ready for recycling. However, the new cover typography (July 2008) immediately caught my eye. The title font was crisp and simple, recalling the all-caps, squarish characters of a teletype from the 1950 s, very post-modern.

Flipping through the pages, I was struck first by the new design-clean and cool yet serious, informationdense, with narrow margins. And with articles on model checking, XML, transactional memory, and more, I actually wanted to read it. Beginning with the interview with Emerson, Clarke, and Sifakis, I then read the article on the history of IT in India and the article on quantum computing before I came to the Editor's Letter describing the makeover.

I had somehow missed that $\mathrm{Com}^{-}$ munications was being overhauled. All I can say is: The editors, staff, and contributors have done an amazing job. I've never really spent time thinking about ACM as an organization, but having a professional journal of this quality makes me proud to be a member.

Henry Kautz, Rochester, NY

Congratulations on the first issue of the new Communications (July 2008). The lineup of all-star authors (some of my favorite people in the field) and the relevant topics were amazing. It's wonderful to see computing's flagship journal return to such a high level of quality. The blend of code, programming-model, language, architecture, education, legal, and business topics represented an inspirational cross-section of the industry.

The issue reminded me how much fun it is to be a computer scientist. Reading it from cover to cover made me even more proud to sign my email...chaiken@acm.org.

David Chaiken, Menlo Park, CA

\section{Correction}

Due to a copy-editing error, a comma was added to the name of one of the authors of the Research Highlights paper "Wake Up and Smell the Coffee: Evaluation Methodology for the 21st Century" (Aug. 2008). Our apologies to J. Eliot B. Moss.

Communications welcomes your opinion. To submit a Letter to the Editor, please limit your comments to 500 words or less and send to letters@cacm.acm.org. 